\title{
Efficiency Analysis of Government Subsidy and Performance Guarantee Policies in Relation to PPP Infrastructure Projects
}

\author{
Lei Shi $\mathbb{D}^{1},{ }^{1}$ Yujia He ${ }^{(D},{ }^{1}$ Masamitsu Onishi $(\mathbb{D}),{ }^{2}$ and Kiyoshi Kobayashi ${ }^{3}{ }^{3}$ \\ ${ }^{1}$ Department of Construction Management, Dalian University of Technology, Dalian 116024, China \\ ${ }^{2}$ Disaster Prevention Research Institute, Kyoto University, Kyoto 611-0011, Japan \\ ${ }^{3}$ Graduate School of Management, Kyoto University, Kyoto 606-8501, Japan \\ Correspondence should be addressed to Lei Shi; leishi@dlut.edu.cn
}

Received 25 September 2017; Revised 16 January 2018; Accepted 4 February 2018; Published 6 March 2018

Academic Editor: Emilio Jiménez Macías

Copyright (@) 2018 Lei Shi et al. This is an open access article distributed under the Creative Commons Attribution License, which permits unrestricted use, distribution, and reproduction in any medium, provided the original work is properly cited.

\begin{abstract}
Sustainable operation of public-private partnership (PPP) infrastructure projects that are characterized by considerable external benefits is of vital importance. However, a liquidity shock might trigger an inefficient liquidation of a project by the special purpose vehicle (SPV) and the bank, whose objectives are to maximize the profits generated by the project. This study argues that performance guarantee and subsidy policies implemented by the government play a role in encouraging socially efficient decisionmaking by the SPV and the bank to ensure the continuation of socially valuable projects. The results show that both government subsidy and performance guarantee policies are effective in avoiding the inefficient liquidation of PPP infrastructure projects when the external benefits are large and certain. However, a performance guarantee policy might lead to inefficient continuation when the external benefits of a project are uncertain. Finally, we discuss the possibility that an integrated policy combining performance guarantees and government subsidies improves the efficiency of a PPP infrastructure project.
\end{abstract}

\section{Introduction}

Pioneered in the United Kingdom through the private finance initiative in 1992 [1], an innovative project scheme, the publicprivate partnership (PPP) approach, has been adopted for the procurement of a wide variety of infrastructure services in countries with various levels of wealth on all continents [2-4]. The demand for infrastructure services increases with the economic and social development. If the provision of the infrastructure services is reduced or interrupted, it is likely to result in significant losses, not only for end users, but also for the local and national economies. Therefore, the supply of infrastructure services via the PPP approach must be stable and sustainable.

In a PPP infrastructure project, a public authority (a local or central government or a government agency) enters into a concession contract with a special purpose vehicle (SPV) set up by private sponsor companies for the delivery of public services. Since a PPP infrastructure project, such as urban rail transit and sewage treatment plant, usually involves a large upfront investment, the SPV raises funds mainly through debt [5]. However, unanticipated additional investments might be needed during the long life of the PPP infrastructure project. For instance, a sudden change in either the natural or economic environment may lead to an increase in operating costs. If the SPV that is lack of enough liquidity cannot raise sufficient funds to cover the additional costs, it will fail to fulfill its contract obligations. This is termed a liquidity shock problem [6].

The liquidate shock problem can be avoided via a successful renegotiation between the SPV and the bank. In the renegotiation, the bank will provide an additional loan to the SPV if it finds that the continuation of the project is valuable [7]. However, the bank may not provide the additional loan even for the valuable project when the liquidity shock occurs, because it concerns that the private company exploits the advantage of asymmetric information against the bank for its own benefit [8]. However, assuming there is no asymmetry of information between the SPV and the bank, the latter who only considers the financial revenues 
from the PPP infrastructure project may refuse to rescue the PPP infrastructure project with large external benefits when the liquidity shock occurs.

This paper aims to analyze the roles of performance guarantee policies and government subsidy policies in encouraging socially efficient decision-making by the SPV and the bank to ensure the continuation of socially valuable projects facing liquidity shock. We consider two cases in relation to external benefits of the PPP infrastructure project: large and certain external benefits and uncertain external benefits. In the former case, we show that both policies are effective in avoiding inefficient project liquidation, because they incentivize the bank to provide additional lending to the SPV when the liquidity occurs. In the latter case, we argue that government subsidy policies may improve the project efficiency because they allow the government to intervene ex post depending on the realized external benefits. However, performance guarantee policies may trigger an inefficient project continuation when the external benefits become small. Finally, we propose an integrated policy combining a performance guarantee policy and a government subsidy policy, and examine the possibility of improving the efficiency of the PPP infrastructure projects.

The remainder of this paper is organized as follows. Section 2 is a literature review. Section 3 outlines a threeperiod model that is used to investigate the liquidation and continuation mechanisms of a PPP infrastructure project following a liquidity shock. We analyze the roles of performance guarantee policies and government subsidy policies in avoiding inefficient liquidation when the external benefits of the PPP infrastructure project are large and certain. Section 4 describes an extension of the basic model to investigate the different effects of performance guarantee policies and government subsidy policies on decision-making by the SPV and the bank regarding the continuation or liquidation of a project when the external benefits are uncertain, and examines the effect of the integrated policy that we propose. Section 5 presents a simple numerical example to demonstrate the application of our model. Section 6 discusses the results of the analysis. Section 7 concludes and provides a summary of issues to be investigated in future studies.

\section{Literature Review}

How to introduce government regulatory policies to incentivize the SPV and bank to choose socially efficient decisionmaking has drawn considerable attentions [9-11]. In particular, performance guarantee policies and government subsidy policies are widely used in PPP infrastructure projects [1214]. The performance guarantee policies are designed to safeguard against performance risks, as the government will confiscate the guarantee money if the SPV fails to provide the predetermined services [15]. Myers and Najafi analyzed the benefit-cost of performance guarantee for avoiding project default [16]. Shi et al. found that the performance guarantee is effective in deterring the strategic breach of contract by the SPV in transport PPP infrastructure projects [17]. On the other hand, government subsidy policies are usually invoked to address the gap between the high production costs involved in infrastructure generation and subsequent revenue inflow $[18,19]$. Scholars discussed the impacts of government subsidy policies on the efficiency of the PPP infrastructure projects, with a focus on the incentive effects [20,21]. Couture and Gagnon found that government subsidy policies can ensure a reasonable rate of return for the producer, which helps to attract private participants to PPP infrastructure projects [22]. Wu et al. found that the government subsidy based on the expected cost and revenue could provide the SPV with an incentive to invest more in construction and operation [23].

In contrast with previous research, this paper focuses on the external benefits of PPP infrastructure projects that have been ignored by far. PPP infrastructure projects include considerable external benefits that are not reflected in the cash flows generated by the project [24]. The amount of revenue earned by the SPV is usually less than the value of the external benefits from the project. In other words, the PPP infrastructure project generates considerable external benefits that do not return to the SPV as profit. Private participants in a PPP infrastructure project such as the SPV and the bank, which both aim to maximize their profits, may inefficiently liquidate a socially valuable project because they take no account of the project's external benefits; that is, liquidity shock occurs. To avoid the social loss caused by the liquidity shock, government regulations that consider the external benefits of the PPP infrastructure project are necessary.

The present study complements the literature in the following two aspects. First, we propose new approach to solve the liquidity shock problem occurring in PPP infrastructure projects characterized by large external benefits. In order to avoid the inefficient liquidation, we argue that two policies can provide the SPV and the bank who take no account of the project's external benefits with proper incentives to ensure the continuation of socially valuable projects. Second, we develop a theoretical model to investigate the impacts of performance guarantee and government subsidy in terms of direct government payments on decision-making by the SPV and bank, which however have been overlooked in existing studies.

\section{Model with Certain External Benefits}

We consider theoretical model that consists of three periods to analyze the decision-making by the SPV, the bank, and the government in a PPP infrastructure project with certain and large external benefits. We will consider the case where the external benefits are uncertain in the following section. As shown in Figure 1, at $t=1$, the SPV signs a concession contract with the government. Assume that the SPV has no equity fund and raises funds via a loan from the bank for the initial investment. At $t=2$, an additional investment is needed to cover operating expenditure. This is termed a liquidity shock. After the liquidity shock occurs, the SPV needs to renegotiate with the bank for an additional loan. The PPP infrastructure project will be liquidated if the SPV fails to raise the additional loan. If the loan is provided by the bank, the project continues and the SPV receives revenue $R$ at $t=3$. 


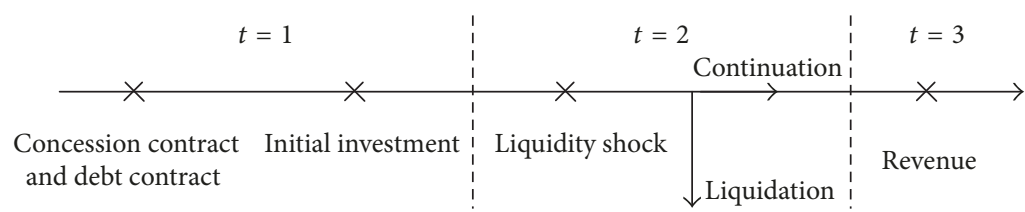

Figure 1: Time frame of the model.

Government subsidy policies and performance guarantee policies are government intervention tools to prevent inefficient liquidation after a liquidity shock occurs at $t=2$. The government can indirectly encourage the bank to provide the additional loan by paying the SPV a subsidy that can be used to repay the debt. Performance guarantee policies require the government to impose a guarantee amount on the SPV at the beginning of the project, that is, at $t=1$. When the SPV continues the project until $t=3$, the guarantee amount is returned to the SPV who can then use it to repay the debt. Assume that the SPV has no initial endowment; thus, the performance guarantee has to be borrowed from the bank.

Assume that all decision-makers are risk neutral with an additive separable utility function over undiscounted consumption streams. The objectives of the SPV and the bank are to maximize their profits, while those of the government are to ensure the social efficiency of project, for example, avoiding the liquidation of the project with large external benefits.

Assumptions. (1) The distribution function of liquidity shock $\rho$ is denoted by $F(\rho)$ and the density function by $f(\rho)$. We assume that the project's net present value is nonnegative:

$$
R-E(\rho)-I \geq 0,
$$

where $E(\rho)$ represents the expected value of the stochastic variable $\rho$.

(2) The PPP infrastructure project is characterized by the existence of external benefits valued at $W$. Because the initial investment is already sunk at $t=1$, the condition whereby continuation of the project is socially efficient at $t=2$ can be written as $R+W \geq \rho$. We assume that continuation is always efficient despite any arbitrary liquidity shock in the basic model:

$$
R+W \geq \bar{\rho} .
$$

Later, we will discuss the case in which project liquidation is efficient when the external benefits are small in the following section.

(3) When the liquidity shock $\rho$ is sufficiently large, the SPV's payoff is assumed to be negative:

$$
R<\bar{\rho}
$$

Given the above assumptions, we have the following lemma.

Lemma 1. The condition for additional loan to be made available is written as

$$
\rho \leq R
$$

The left-hand side of (4) represents the amount of the additional loan, and the right-hand side of (4) represents the maximum payoff the bank can obtain after providing the additional loan. At this point, the initial loan $I$ is a sunk cost, which therefore is not considered in the renegotiation. From Lemma 1, we can see that the bank does not consider the external benefits $W$ when deciding whether to provide the additional loan or not. Lemma 1 also indicates that provision of additional loan is impossible if $\rho>R$. As a result, the project is always inefficiently liquidated, even though continuation remains socially efficient even after the liquidity shock $\rho \in$ $[R, \bar{\rho}]$ occurs.

3.1. Effect of the Government Subsidy Policy. We analyze the effect of the government subsidy policy on the efficiency of PPP infrastructure projects facing a liquidity shock. Consider the case where the government pays a subsidy to the SPV when the additional loan is not provided by the bank. From Lemma 1, this occurs only when the liquidity shock $\rho$ is larger than the revenue $R$. Suppose that both the SPV and the bank know that the government subsidy policy will be applied in this case. Furthermore, the magnitudes of the revenue $R$ and the liquidity shock $\rho$ are common knowledge to the SPV, the bank, and the government. When $0<\rho \leq R$, the additional loan will be provided without the subsidy. However, when $R<\rho \leq \bar{\rho}$, the additional loan is not available unless the government subsidy policy is applied. In this case, the minimum subsidy is determined to be $\rho-R$.

However, because the subsidy comes from tax funds, there is a welfare loss. Now, assume that a taxpayer pays $1+\lambda$ when the government raises one unit of tax. Parameter $\lambda$ is called a shadow price, which suggests that when the value of $\lambda$ is higher, the welfare loss (deadweight loss) is greater. Therefore, the welfare loss incurred by paying the subsidy is written as $\lambda \int_{R}^{\bar{\rho}}(\rho-R) f(\rho) d \rho$.

The effect of introducing the government subsidy policy is expressed as

$$
\begin{gathered}
\int_{R}^{\bar{\rho}}(R+W-\rho) f(\rho) d \rho-\lambda \int_{R}^{\bar{\rho}}(\rho-R) f(\rho) d \rho \\
\quad=W\{1-F(R)\}-(1+\lambda) \int_{R}^{\bar{\rho}}(\rho-R) f(\rho) d \rho .
\end{gathered}
$$

The first term in (5) represents the value of the external benefits that are realized by avoiding inefficient liquidation, while the second term shows the social cost incurred by introducing the government subsidy policy. Equation (5) suggests that the effect of the government subsidy policy will 
be small or even negative if the welfare loss is sufficiently large or the value of the external benefits is not significant.

3.2. Effect of the Performance Guarantee Policy. Previously, we found that inefficient liquidation can be avoided by introducing a government subsidy policy, although this generates a social welfare loss. In this section, we consider the effect of the performance guarantee policy on the efficiency of the project. Now, consider the additional investment problem when the performance guarantee policy is introduced. Since the SPV obtains $R+D$, which can be used to repay the debt when the project continues until $t=3$, the continuation and liquidation condition can be rewritten as

$$
\begin{aligned}
& \rho \leq R+D \longrightarrow \text { Continuation, } \\
& \rho>R+D \longrightarrow \text { Liquidation. }
\end{aligned}
$$

Because the amount of the guarantee is determined prior to the occurrence of the liquidity shock, it is set as $D=\bar{\rho}-R$ to ensure that the project will be continued under any $\rho$. Note that there is no welfare loss incurred. The effect of introducing the performance guarantee policy is expressed as

$$
\begin{aligned}
& \int_{R}^{\bar{\rho}}(R+W-\rho) f(\rho) d \rho \\
& \quad=W\{1-F(R)\}-\int_{R}^{\bar{\rho}}(\rho-R) f(\rho) d \rho .
\end{aligned}
$$

Given assumption condition (2), the value of (7) is always positive, which indicates that the performance guarantee policy is successful in preventing inefficient liquidation of the project without any social loss under the assumption that the external benefits are certain and sufficiently large.

\section{Model with Uncertain External Benefits}

4.1. Assumptions. The continuation of a PPP infrastructure project with significant external benefits is guaranteed by the introduction of either a government subsidy policy or a performance guarantee policy. However, assumption condition (2) in the previous section does not always hold in practice. In particular, the forecast external benefits $W$ may become small at $t=2$. Now, we extend the model to consider the case where the external benefits $W$ are uncertain at $t=1$. Assume that the value of the external benefits $W$ is given as follows:

$$
W= \begin{cases}\bar{W}, & \text { with probability } p \\ 0, & \text { with probability } 1-p .\end{cases}
$$

The assumption conditions (1) and (3) are still presumed to hold. In the case where the value of the external benefits is low, the continuation of a project facing a liquidity shock may not be socially efficient. Consider the case in which the external benefits are valued at $W=\bar{W}$. Denote the threshold value of the liquidity shock that distinguishes between efficient continuation and efficient liquidation by $\rho^{*}(W=\bar{W})=R+\bar{W}$. That is, the continuation will be socially efficient only when $\rho<\rho^{*}(W=\bar{W})$; otherwise, liquidation will be efficient. Conversely, when $W=0$, the corresponding threshold value for the liquidity shock $\rho^{*}(\bar{W}=0)=R$.

4.2. The Optimal Performance Guarantee Amount in the Performance Guarantee Policy. At $t=1$, the government determines the amount of the guarantee denoted by $\widehat{D}$, which satisfies $0 \leq \widehat{D}<\bar{W}$. When $\rho \leq R+\widehat{D}$, additional loan is always available, no matter what value of external benefits $W$ is realized. On the contrary, the project is liquidated when $\rho>R+\widehat{D}$. First, consider the case where the value of the realized external benefits $W=\bar{W}$. The project is always efficiently continued (liquidated) when $\rho \leq \rho^{*}(W=\bar{W})(\rho>$ $\left.\rho^{*}(W=\bar{W})\right)$. However, inefficient liquidation occurs when $\rho \in(R+\widehat{D}, R+\bar{W})$. The social loss generated by inefficient liquidation is expressed as $\int_{R+\widehat{D}}^{R+\bar{W}}(R+W-\rho) f(\rho) d \rho$.

Next, consider the case where the value of the realized external benefits $W=0$. The project is efficiently continued (liquidated) when $\rho \leq \rho^{*}(\bar{W}=0)\left(\rho>\rho^{*}(\bar{W}=\right.$ $0))$. However, the project is inefficiently continued when $\rho \in(R, R+\widehat{D})$. The social loss generated by inefficient continuation is expressed as $\int_{R}^{R+\widehat{D}}(\rho-R) f(\rho) d \rho$.

Therefore, the total social loss from adopting the performance guarantee policy is expressed as

$$
\begin{aligned}
L_{d}(\widehat{D})= & p \int_{R+\widehat{D}}^{R+\bar{W}}(R+\bar{W}-\rho) f(\rho) d \rho \\
& +(1-p) \int_{R}^{R+\widehat{D}}(\rho-R) f(\rho) d \rho .
\end{aligned}
$$

The first term represents the social loss arising from inefficient liquidation and the second term represents the social loss brought about by inefficient continuation. The marginal increase in the guarantee amount reduces the expected social cost generated by inefficient liquidation. However, it also increases the social cost from inefficient continuation. In this sense, the optimal guarantee amount depends on the tradeoff between the first and second terms of (9) under the condition of uncertain external benefits.

Therefore, the problem of determining the optimal guarantee amount is formulated as

$$
\min _{\widehat{D}} L_{d}(\widehat{D})
$$

For problem (10), we obtain

$$
\widehat{D}^{*}=p \bar{W}
$$

Since the social loss arising from inefficient liquidation when $W=\bar{W}$ without the adoption of a performance guarantee policy can be expressed as $p \int_{R}^{R+\bar{W}}(R+\bar{W}-\rho) f(\rho) d \rho$, 
the effect of adoption of a performance guarantee policy can be written as

$$
\begin{aligned}
\Phi\left(R, R+\widehat{D}^{*}\right)= & p \int_{R}^{R+\bar{W}}(R+\bar{W}-\rho) f(\rho) d \rho \\
& -L_{d}\left(\widehat{D}^{*}\right) \\
= & p \bar{W}\{F(R+p \bar{W})-F(R)\} \\
& -\int_{R}^{R+p \bar{W}}(\rho-R) f(\rho) d \rho .
\end{aligned}
$$

Since $d \Phi\left(R, R+\widehat{D}^{*}\right) / d p=\bar{W}\{F(R+p \bar{W})-F(R)\} \geq 0$ always holds, we have the following proposition.

Proposition 2. When the external benefits of the PPP infrastructure project are uncertain, the effect of the performance guarantee policy, $\Phi\left(R, R+\widehat{D}^{*}\right)$, is nondecreasing with the probability that the large external benefits $\bar{W}$ occur, $p$.

4.3. Effect of the Government Subsidy Policy. Now, consider the case where only a government subsidy policy is introduced. The government pays the subsidy to the SPV only when continuation of the project is efficient, after knowing the real value of the external benefits. In this sense, inefficient continuation or liquidation can be avoided by introducing a government subsidy policy because the decision about the subsidy can be made based on the realized external benefits. However, a deadweight loss occurs following the introduction of the government subsidy policy.

When the value of the realized external benefits $W=0$, the project is efficiently continued or liquidated without any subsidy being paid. However, when $W=\bar{W}$, the government pays a subsidy equivalent to $\rho-R$ after the liquidity shock $\rho$ occurs. Consequently, the social loss that is incurred as a result of introducing the government subsidy policy can be written as $L_{c}=p \lambda \int_{R}^{R+\bar{W}}(\rho-R) f(\rho) d \rho$.

Therefore, the effect of the government subsidy policy can be expressed as

$$
\begin{aligned}
& \Psi(R, R+\bar{W})=p \int_{R}^{R+\bar{W}}(R+\bar{W}-\rho) f(\rho) d \rho-L_{c} \\
& \quad=p[\bar{W}\{F(R+\bar{W})-F(R)\} \\
& \left.\quad-(1+\lambda) \int_{R}^{R+\bar{W}}(\rho-R) f(\rho) d \rho\right] .
\end{aligned}
$$

As discussed above, the government subsidy policy is not necessary when the value of the real external benefits is low. In other words, the decision-making regarding continuation or liquidation during the implementation period of the project is always efficient when a government subsidy policy is introduced. However, the effect of the government subsidy policy is evaluated by comparing the tradeoff between the benefits from avoiding inefficient liquidation and the welfare loss incurred as a result of the introduction of the government subsidy policy. The greater the real value of the external benefits is or the smaller the welfare loss is, the more effective the government subsidy policy becomes. In addition, $\partial \Psi(R, R+\bar{W}) / \partial \lambda=-p \int_{R}^{R+\bar{W}}(\rho-R) f(\rho) d \rho \leq 0$, and we have the following proposition.

Proposition 3. When the external benefits of the PPP infrastructure project are uncertain, the effect of the government subsidy policy, $\Psi(R, R+\bar{W})$, is nonincreasing with the shadow price, $\lambda$.

4.4. An Integrated Policy. Under the condition where the value of the external benefits of the PPP infrastructure project is uncertain, a performance guarantee policy might trigger either efficient continuation or liquidation. Conversely, the government can determine the optimal subsidy amount after knowing the real value of the external benefits. In this sense, a government subsidy policy always ensures the efficiency of a PPP infrastructure project, although it also results in a welfare loss. In summary, neither a guarantee nor a government subsidy policy can completely avoid a social loss when the external benefits of the PPP infrastructure project are uncertain.

With the aim of improving the effectiveness of both the performance guarantee policy and the government subsidy policy, we now examine an integrated policy that combines various features of these two policies. First, we extend the model analyzed in Sections 4.2 and 4.3 and consider the situation when the government pays the SPV a subsidy after determining the real value of the external benefits $W$ given the guarantee amount $\widetilde{D}$. Then, we find the optimal guarantee amount. Finally, we compare the effect of the integrated policy with those of the two original policies.

As shown in Table 1, given the guarantee amount $\widetilde{D}$, the government will pay the SPV a subsidy to avoid inefficient liquidation only when the value of the external benefits $W=$ $\bar{W}$ and the liquidity shock $\rho \in(R+\widetilde{D}, R+\bar{W})$. The amount of the subsidy is given by $\rho-R-\widehat{D}$, which brings about a welfare loss of $\lambda \int_{R+\widetilde{D}}^{R+\bar{W}}(\rho-R-\widetilde{D}) f(\rho) d \rho$. In other situations, the government will not pay the subsidy either because liquidation of the project is socially efficient $(W=$ $\bar{W}, \rho \geq R+\bar{W}$ or $W=0, \rho>R+\widetilde{D}$ ) or because the bank will provide an additional loan to ensure continuation of the project even without the government subsidy $(W=$ $\bar{W}, \rho<R+\widetilde{D}$ or $W=0, \rho \leq R+\widetilde{D})$. Among these situations, inefficient continuation of the project will occur when $W=0$ and $\rho<R+\widetilde{D}$. The social loss is expressed as $\int_{R}^{R+\widetilde{D}}(\rho-R) f(\rho) d \rho$.

Therefore, the social loss incurred by adopting the integrated policy can be expressed as

$$
\begin{aligned}
L_{h}(\widetilde{D})= & p \lambda \int_{R+\widetilde{D}}^{R+\bar{W}}(\rho-R-\widetilde{D}) f(\rho) d \rho \\
& +(1-p) \int_{R}^{R+\widetilde{D}}(\rho-R) f(\rho) d \rho .
\end{aligned}
$$


TABLE 1: The conditions for the payment of the government subsidy.

\begin{tabular}{lccccc}
\hline $\begin{array}{l}\text { External } \\
\text { benefit }\end{array}$ & Liquidity shock & $\begin{array}{c}\text { Continuation or } \\
\text { liquidation (without } \\
\text { subsidy) }\end{array}$ & Social efficiency & Subsidy & Social loss \\
\hline$W=\bar{W}$ & $\rho<R+\widetilde{D}$ & Continuation & 0 & $\times$ & - \\
& $\rho \in(R+\widetilde{D}, R+\bar{W})$ & Liquidation & $\times$ & 0 & $\lambda \int_{R+\widetilde{D}}^{R+\bar{W}}(\rho-R-\widetilde{D}) f(\rho) d \rho$ \\
$W=0$ & $\rho \geq R+\bar{W}$ & Liquidation & Continuation & $\times$ & $\times$ \\
\hline
\end{tabular}

Note. The $\bigcirc$ and $\times$ signs in the "social efficiency" column mean that the outcomes (continuation or liquidation) after the occurrence of the liquidity shock when only the performance guarantee policy is adopted are socially efficient or socially inefficient, respectively. The O sign in the "subsidy" column means that the government pays the subsidy to the SPV, while the $\times$ sign means that the government does not pay the subsidy. The - signs in the "social loss" column mean that there is no social loss.

The problem of determining the optimal amount of the guarantee is formulated as

$$
\min _{\widehat{D}} L_{h}(\widetilde{D})
$$

For problem (15), we obtain

$$
\begin{aligned}
p \lambda & \left\{F(R+\bar{W})-F\left(R+\widetilde{D}^{*}\right)\right\} \\
& =(1-p) \widetilde{D}^{*} f\left(R+\widetilde{D}^{*}\right) .
\end{aligned}
$$

If the integrated policy is not adopted, the social loss that is incurred is expressed as $p \int_{R}^{R+\bar{W}}(R+\bar{W}-\rho) f(\rho) d \rho$. Thus, the effect of the integrated policy can be written as

$$
\Xi_{h}(\widetilde{D})=p \int_{R}^{R+\bar{W}}(R+\bar{W}-\rho) f(\rho) d \rho-L_{h}(\widetilde{D}) .
$$

Define $\lambda^{*}=\left\{p \int_{R+\widehat{D}^{*}}^{R+\bar{W}}(R+\bar{W}-\rho) f(\rho) d \rho+(1-\right.$ p) $\left.\int_{R+\widetilde{D}^{*}}^{R+\widehat{D}^{*}}(\rho-R) f(\rho) d \rho\right\} / p \int_{R+\widetilde{D}^{*}}^{R+\bar{W}}\left(\rho-R-\widetilde{D}^{*}\right) f(\rho) d \rho, \lambda^{* *}=$ $(1-p) \int_{R}^{R+\widetilde{D}^{*}}(\rho-R) f(\rho) d \rho / p\left\{\int_{R}^{R+\widetilde{D}^{*}}(\rho-R) f(\rho) d \rho+\right.$ $\left.\int_{R+\widetilde{D}^{*}}^{R+\bar{D}} \widetilde{D}^{*} f(\rho) d \rho\right\}$; we have the following propositions.

Proposition 4. When the external benefits of the PPP infrastructure project are uncertain, the integrated policy is more effective than the performance guarantee policy if and only if $\lambda \leq \lambda^{*}$.

Proof. Given (12), (17) can be rewritten as

$$
\begin{aligned}
& \Xi_{h}\left(\widetilde{D}^{*}\right)=\Phi\left(R, R+\widehat{D}^{*}\right) \\
& +p \int_{R+\widehat{D}^{*}}^{R+\bar{W}}(R+\bar{W}-\rho) f(\rho) d \rho \\
& \quad-p \lambda \int_{R+\widetilde{D}^{*}}^{R+\bar{W}}\left(\rho-R-\widetilde{D}^{*}\right) f(\rho)+(1-p) \\
& \quad\left\{\int_{R}^{R+\widehat{D}^{*}}(\rho-R) f(\rho) d \rho\right. \\
& \left.\quad-\int_{R}^{R+\widetilde{D}^{*}}(\rho-R) f(\rho) d \rho\right\},
\end{aligned}
$$

where $\Phi\left(R, R+\widehat{D}^{*}\right)$ represents the effect of only adopting the performance guarantee policy. The sum of the second and third terms represents the net benefit obtained by introducing the subsidy in the integrated policy. The final term expresses the net benefit by introducing difference amount of performance guarantee in the two policies. From (18), we find that the integrated policy is more effective than the performance guarantee policy if and only if

$$
\lambda \leq \lambda^{*}=\frac{p \int_{R+\widehat{D}^{*}}^{R+\bar{W}}(R+\bar{W}-\rho) f(\rho) d \rho+(1-p) \int_{R+\widetilde{D}^{*}}^{R+\widehat{D}^{*}}(\rho-R) f(\rho) d \rho}{p \int_{R+\widetilde{D}^{*}}^{R+\bar{W}}\left(\rho-R-\widetilde{D}^{*}\right) f(\rho) d \rho} .
$$

Finally, we prove the existence of $\lambda$ satisfying (19). From (16), we get the optimal $\widetilde{D}^{*}=0$ when $\lambda=0$. Because $\lambda^{*}(\lambda=0)=\left\{p \int_{R}^{R+\bar{W}}(R+\bar{W}-\rho) f(\rho) d \rho+(1-p) \int_{R}^{R+\widehat{D}^{*}}(\rho-\right.$
R) $f(\rho) d \rho\} / p \int_{R}^{R+\bar{W}}(\rho-R) f(\rho) d \rho>0$, we can find that there exists $\lambda$ satisfying (19). 
Proposition 5. When the external benefits of the PPP infrastructure project are uncertain, the integrated policy is more effective than the government subsidy policy if and only if $\lambda \geq$ $\lambda^{* *}$.

Proof. Given (13), (17) can be rewritten as

$$
\begin{aligned}
\Xi_{h}\left(\widetilde{D}^{*}\right)= & \Psi(R, R+\bar{W}) \\
& +p \lambda \int_{R}^{R+\bar{W}}(\rho-R) f(\rho) d \rho \\
& -p \lambda \int_{R+\widetilde{D}^{*}}^{R+\bar{W}}\left(\rho-R-\widetilde{D}^{*}\right) f(\rho) d \rho \\
& -(1-p) \int_{R}^{R+\widetilde{D}^{*}}(\rho-R) f(\rho) d \rho,
\end{aligned}
$$

where $\Psi(R, R+\bar{W})$ represents the effect of the government subsidy policy only. The sum of the second and third terms expresses the benefits obtained by reducing the deadweight loss when adopting the performance guarantee in the integrated policy. The final term represents the social loss arising from inefficient continuation as a result of adopting the performance guarantee in the integrated policy. From (20), we conclude that the integrated policy is more effective than the government subsidy policy if and only if

$$
\begin{aligned}
\lambda & \geq \lambda^{* *} \\
& =\frac{(1-p) \int_{R}^{R+\widetilde{D}^{*}}(\rho-R) f(\rho) d \rho}{p\left\{\int_{R}^{R+\widetilde{D}^{*}}(\rho-R) f(\rho) d \rho+\int_{R+\widetilde{D}^{*}}^{R+\bar{D}} \widetilde{D}^{*} f(\rho) d \rho\right\}} .
\end{aligned}
$$

\section{A Simple Numerical Example}

In this section, we present a simple numerical example to illustrate the case where the external benefits of the PPP infrastructure project are uncertain. To facilitate our analysis, we standardize project revenue $R=1$; the values of other parameters are supposed to be proportional to the revenue $R$. Consider $\bar{W}=2 / 3$, and $\rho \in[0,5 / 3]$. Moreover, suppose that $\rho$ is uniformly distributed, and $f(\rho)=3 / 5, F(\rho)=3 \rho / 5$.

First, we derive the effect of a performance guarantee policy, as shown in Figure 2. In view of $D^{*}=p \bar{W}=$ $2 p / 3$, the effect of a performance guarantee policy, $\Phi(R, R+$ $\left.D^{*}\right)=2 p^{2} / 15$. The simulation result shows that as the probability $p$ increases, the effect of the performance guarantee policy gradually increases. Then, we obtain the effect of a government subsidy policy $\Psi(R, R+\bar{W})=2 p(1-\lambda) / 15$, as shown in Figure 3. By setting $\lambda=0.5, \lambda=1$, and $\lambda=1.5$ (the deadweight loss estimate of $\operatorname{tax}(\lambda)$ usually lies within the range 0 to 1.53; see Stiglitz and Dasgupta [25], Atkinson and Stern [26], Fortin and Lacroix [27], Kleven and Kreiner [28]), respectively, the results show that the effect of the government subsidy decreases as $\lambda$ increases. These observations are exactly consistent with Propositions 2 and 3.

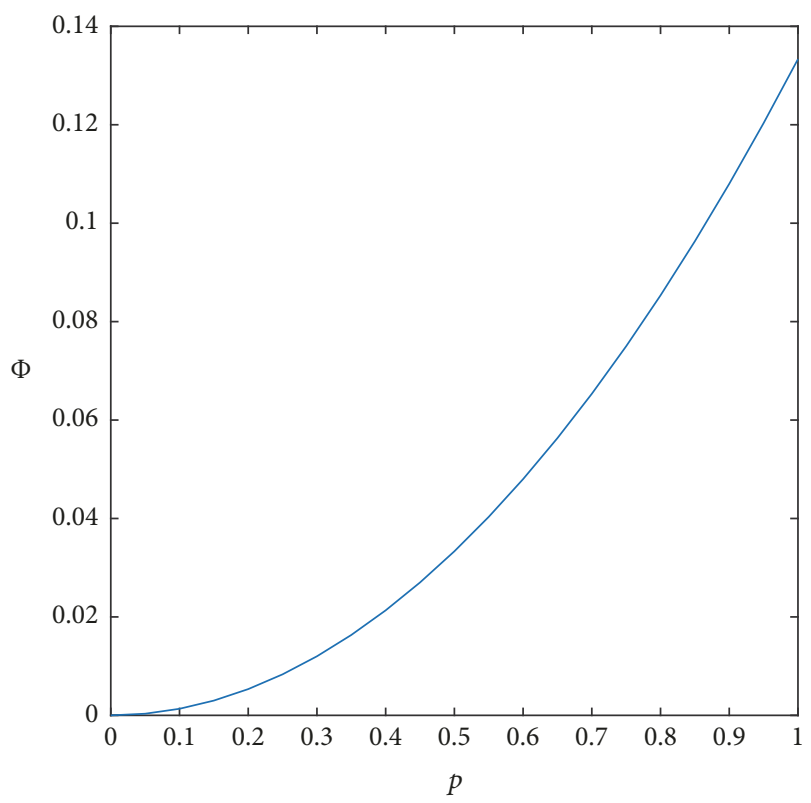

FIGURE 2: Effect of a performance guarantee policy.

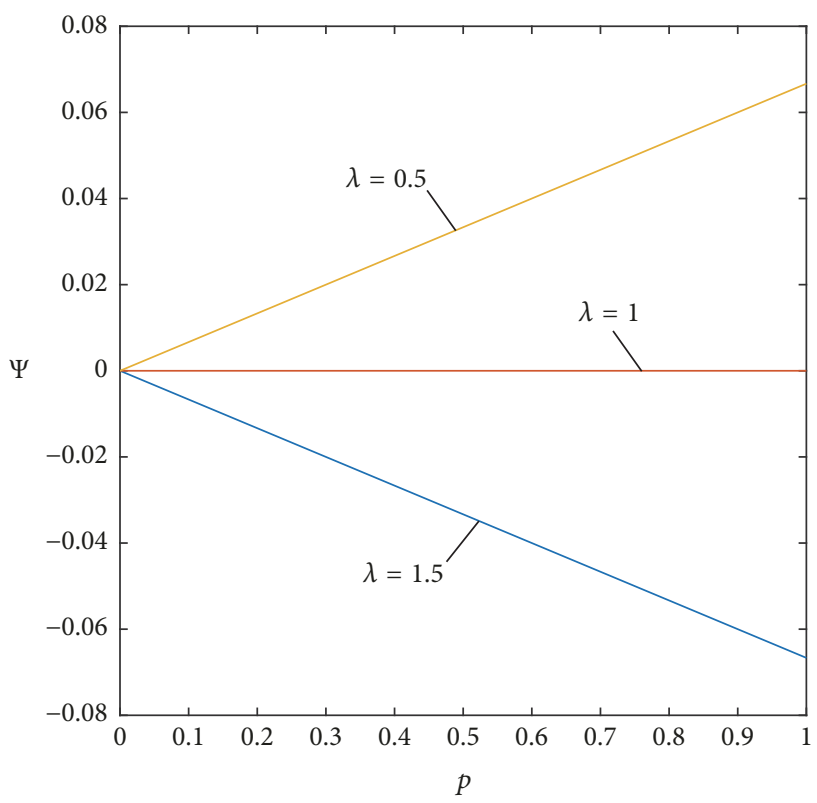

FIGURE 3: Effect of a government subsidy policy $(\lambda=0.5, \lambda=1$, and $\lambda=1.5)$.

Finally, Figures 4 and 5 show the comparative effects of a performance guarantee policy (red line), a government subsidy policy (yellow line), and an integrated policy (blue line). In view of $\widetilde{D}^{*}=2 p \lambda / 3(1-p+p \lambda)$, when $\lambda=0.5$, we find that the integrated policy is the most effective of the three policies, as shown in Figure 4(a). When $\lambda=1$, the effect of the performance guarantee policy is similar to that of the integrated policy, while both are more effective than the government subsidy policy, as shown in Figure 4(b). When $\lambda=1.5$, however, the performance guarantee policy is the most effective of the three policies, while the government 


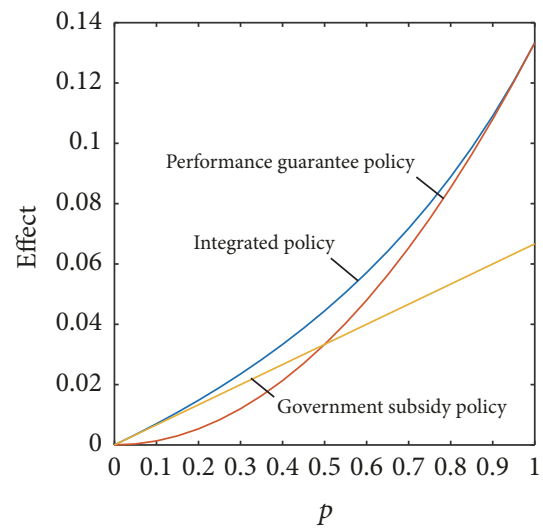

(a)

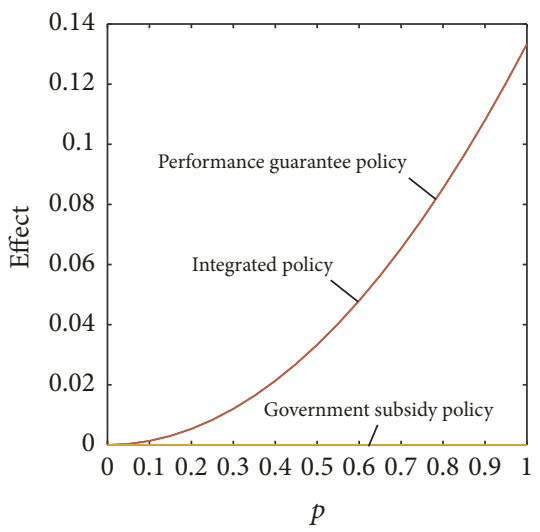

(b)

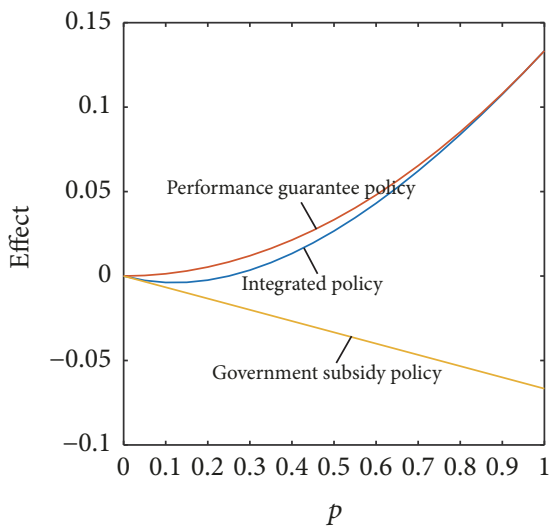

(c)

Figure 4: Policy comparison $(\lambda=0.5$ (a), $\lambda=1$ (b), and $\lambda=1.5$ (c)).

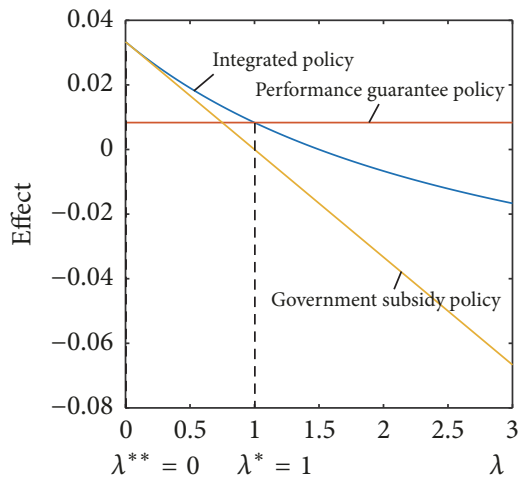

(a)

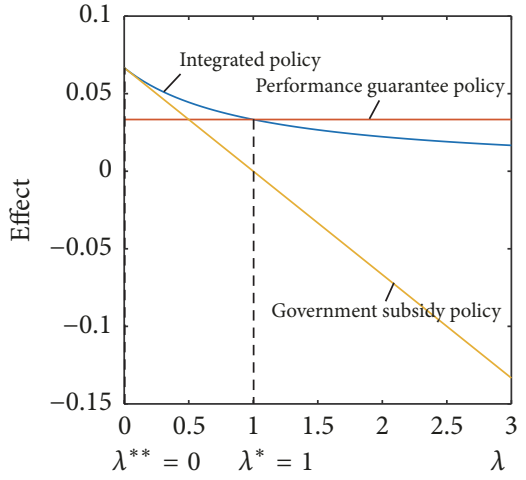

(b)

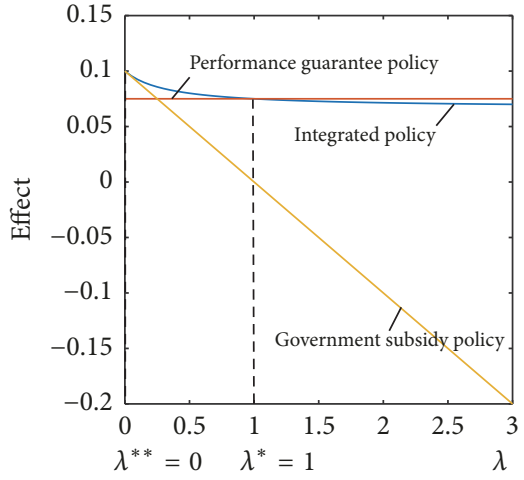

(c)

FIGURE 5: Policy comparison ( $p=0.25$ (a), $p=0.5$ (b), and $p=0.75$ (c)).

subsidy policy will be last choice for the government, as shown in Figure 4(c). The above observations are consistent with the results discussed in Subsection 4.4. In particular, the differences among three policies mainly depend on the shadow price $\lambda$. As shown in Figure 5, when $\lambda$ is small enough, that is, $\lambda \leq \lambda^{*}=1$, the integrated policy is more effective than the performance guarantee policy. On the other hand, when $\lambda \geq \lambda^{* *}=0$, the integrated policy is more effective than the government subsidy policy.

Table 2 shows that when $\lambda$ decreases from 1 to 0.5 and $p$ is constant at 0.4 , the effect of the government subsidy policy increases from 0 to $2.7 \%$, and the effect of the integrated policy increases from $2.1 \%$ to $3.3 \%$, thus the integrated policy turns to be most effective, followed by the government subsidy policy and the performance guarantee policy. When $\lambda$ increases from 1 to 1.5 and $p$ is still constant at 0.4 , the effect of the government subsidy policy decreases from 0 to $-2.7 \%$, and the effect of the integrated policy decreases from $2.1 \%$ to $1.3 \%$, thus the performance guarantee policy is most effective among three policies.

Table 3 shows that when $p$ decreases from 0.5 to 0.25 and $\lambda$ is constant at 0.5 , the effect of the performance guarantee policy decreases from $3.3 \%$ to $0.8 \%$, the effect of the government subsidy policy decreases from $3.3 \%$ to
$1.7 \%$, and the effect of integrated policy decreases from $4.4 \%$ to $1.9 \%$, thus the integrated policy is most effective policy, followed by the government subsidy policy and the performance guarantee policy. When $p$ increases from 0.5 to 0.75 and $\lambda$ is still constant at 0.5 , the effect of the performance guarantee policy increases from $3.3 \%$ to $7.5 \%$, the effect of government subsidy policy increases from $3.3 \%$ to $5 \%$, and the effect of integrated policy increases from $4.4 \%$ to $8 \%$, thus the integrated policy is most effective policy.

\section{Discussion}

A PPP infrastructure project with considerable external benefits might be liquidated during the concession period without intervention by the government. Both a performance guarantee policy and a government subsidy policy play a role in preventing such inefficient liquidation, because they increase the project's cash flow to enable additional borrowing from the bank. A performance guarantee policy is effective in the case where the external benefits of the project are large and less uncertain. However, the amount of the guarantee cannot be determined depending on the external benefits realized ex post. Therefore, a performance guarantee policy may cause a social loss arising from inefficient continuation of the 
TABLE 2: Sensitive analysis regarding $\lambda(p=0.4)$.

\begin{tabular}{lccc}
\hline & & Change rate of $\lambda$ & $\lambda=1.5(+50 \%)$ \\
\hline$\Phi\left(R, R+D^{*}\right)$ & $\lambda=0.5(-50 \%)$ & $\lambda=1$ & $2.1 \%$ \\
$\Psi(R, R+\bar{W})$ & $2.1 \%$ & $2.1 \%$ & $-2.7 \%$ \\
$\Xi_{h}\left(\widetilde{D}^{*}\right)$ & $2.7 \%$ & 0 & $1.3 \%$ \\
\hline
\end{tabular}

TABLE 3: Sensitive analysis regarding $p(\lambda=0.5)$.

\begin{tabular}{lccc}
\hline & & Change rate of $p$ & $p=0.75(+50 \%)$ \\
\hline$\Phi\left(R, R+D^{*}\right)$ & $p=0.25(-50 \%)$ & $p=0.5$ & $7.5 \%$ \\
$\Psi(R, R+\bar{W})$ & $0.8 \%$ & $3.3 \%$ & $5 \%$ \\
$\Xi_{h}\left(\widetilde{D}^{*}\right)$ & $1.7 \%$ & $3.3 \%$ & $8 \%$ \\
\hline
\end{tabular}

project if the external benefits become small. A government subsidy policy is more flexible than a performance guarantee policy in the sense that it allows the government to intervene depending on the realized external benefits. That is, the government can choose whether to pay the SPV the subsidy after observing the external benefits that are realized ex post. However, because the source of the subsidy is tax funds, the provision of a subsidy incurs a deadweight loss. In summary, neither a government subsidy policy nor a performance guarantee policy can prevent inefficient liquidation without incurring a social loss under the condition of uncertain external benefits.

We further examine the possibility that an integrated policy combining a performance guarantee policy and a government subsidy policy improves the social efficiency of PPP infrastructure projects by incorporating the advantages of both types of policies. An integrated policy has two effects that differ from those of a government subsidy policy. On the one hand, the integrated policy can reduce the amount of the subsidy, which reduces the deadweight loss. On the other hand, the integrated policy leads to inefficient continuation of the project through the adoption of a performance guarantee when the external benefits of the project become small. An integrated policy also has two different effects from those of a performance guarantee policy. On the one hand, the integrated policy can avoid inefficient liquidation by introducing a subsidy, although this brings about a deadweight loss. On the other hand, the different optimal performance guarantee amounts determined by the two policies will lead to different levels of social loss arising from inefficient continuation.

Note that the guarantee and subsidy payment should be stipulated in a concession contract. The SPV determines whether to enter the project or not depending on risks under the concession contract. In particular, the existence of liquidation risk increases the cost for procuring an initial fund. Consequently, given the exogenous revenue $R$, the participation condition for the SPV may not be satisfied. To analyze the effect of the liquidation problem on project feasibility, an extended model including an auction to determine the revenue $R$ endogenously should be necessary.

\section{Conclusion}

In this paper, we investigated the mechanism of inefficient liquidation and inefficient continuation of a PPP infrastructure project, with a focus on external benefits, which are a key characteristic of PPP infrastructure projects. We concluded that both a performance guarantee policy and a government subsidy policy can prevent inefficient liquidation after a liquidity shock. However, given the uncertainty of the value of the external benefits, the performance guarantee policy failed to control the incentives for the SPV and the bank to efficiently decide whether to continue or liquidate the project based on the ex post realized external benefits. As a result, the adoption of a performance guarantee policy may cause a social loss arising from inefficient continuation, although it may also reduce the possibility of inefficient liquidation. This finding has not been mentioned in existing studies. Our analysis shows that there is a possibility that an integrated policy combining a performance guarantee policy and a government subsidy policy improves the efficiency of PPP infrastructure projects.

A practical interpretation of our results is that the government interventions are essential for dealing with the liquidation problem caused by liquidity shock occurring in PPP infrastructure projects. In particular, the government could choose the optimal policy (performance guarantee policy, government subsidy policy, or integrated policy), depending on the deadweight loss $\lambda$, the uncertainty of external benefits of the project (probability $p$ ), and the expectation of a liquidity shock $\rho$, to ensure a socially valuable project to be continued with minimum social loss.

Some issues remain to be addressed in future studies. Firstly, because the guarantee amount will not be returned to the SPV if the project is liquidated during the concession period, a performance guarantee policy should provide the SPV with incentives to maximize project performance. Conversely, a government subsidy policy may lead to the moral hazard problem, also known as the soft budget constraint problem, because the subsidy can be used to bail out the SPV ex post after a project is liquidated. Future studies should 
focus on the effects of performance guarantee and government subsidy policies on incentives for the SPV's managerial efforts. Secondly, we disregard the capital structure of the SPV to focus on the effects of performance guarantees and government subsidies on the efficiency of PPP infrastructure projects. However, the optimal capital structure for a PPP infrastructure project plays an essential role in alleviating the adverse effects of a liquidity shock. Finally, we have not yet developed a technique to calculate the size of the performance guarantee and government subsidy that should be paid in reality. Thus, quantitative analysis of the optimal policy settings should be carried out in the future.

\section{Appendix}

To make the paper more readable so that readers do not have to recheck the meanings of some notations back and forth, Notations provides a list of some frequently used notations.

\section{Notations}

I: $\quad$ Initial investment

$\rho: \quad$ Liquidity shock or additional investment or the additional loan

$\bar{\rho}: \quad$ Upper limit of the liquidity shock

$\rho^{*}:$ The threshold value of the liquidity shock that distinguishes between efficient continuation and liquidation

$F(\rho)$ : Distribution function of the liquidity shock

$f(\rho)$ : Density function of the liquidity shock

$E(\rho)$ : Expected value of the liquidity shock

$R: \quad$ The revenue SPV received

$D$ : The amount of performance guarantee

$W$ : External benefits of the PPP infrastructure project

$\bar{W}: \quad$ Upper bound value of external benefits

$p$ : The probability that the large external benefits are achieved

$\lambda$ : $\quad$ Shadow price of government subsidy

$\widehat{D}$ : $\quad$ Performance guarantee in the performance guarantee policy

$\widehat{D}^{*}$ : The optimal performance guarantee in the performance guarantee policy

$\widetilde{D}: \quad$ Performance guarantee in the integrated policy

$\widetilde{D}^{*}:$ The optimal performance guarantee in the integrated policy

Ф: $\quad$ The effect of the performance guarantee policy

$\Psi: \quad$ The effect of the government subsidy policy

$\Xi: \quad$ The effect of the integrate policy

$\lambda^{*}$ : The threshold value of the shadow price under which the integrated policy is more effective than the performance guarantee policy $\lambda^{* *}$ : The threshold value of the shadow price beyond which the integrated policy is more effective than the government subsidy policy.

\section{Conflicts of Interest}

The authors declare that there are no conflicts of interest regarding the publication of this article.

\section{Acknowledgments}

The authors would like to thank NSFC for its financial support for this research (Grant no. 71672017).

\section{References}

[1] P. A. Grout, "The economics of the private finance initiative," Oxford Review of Economic Policy, vol. 13, no. 4, pp. 53-66, 1997.

[2] J. L. Guasch, J.-J. Laffont, and S. Straub, "Renegotiation of concession contracts in Latin America. Evidence from the water and transport sectors," International Journal of Industrial Organization, vol. 26, no. 2, pp. 421-442, 2008.

[3] S. Verweij, "Producing satisfactory outcomes in the implementation phase of PPP infrastructure projects: A fuzzy set qualitative comparative analysis of 27 road constructions in the Netherlands," International Journal of Project Management, vol. 33, no. 8, article no. 1804, pp. 1877-1887, 2015.

[4] C. Gordon, “The challenges of transport PPP's in low-income developing countries: A case study of Bangladesh," Transport Policy, vol. 24, pp. 296-301, 2012.

[5] J. Delmon, Private Sector Investment in Infrastructure: Project Finance, PPP Projects and Risks, Kluwer Law International, 2009, https://books.google.ca/books?id=vHdhB6jyjBIC.

[6] B. Holmström and J. Tirole, "Private and public supply of liquidity," Journal of Political Economy, vol. 106, no. 1, pp. 1-40, 1998.

[7] D. W. Diamond, "Debt Maturity Structure and Liquidity Risk," The Quarterly Journal of Economics, vol. 106, no. 3, pp. 709-737, 1991.

[8] D. W. Diamond and R. G. Rajan, "Liquidity risk, liquidity creation, and financial fragility: A theory of banking," Journal of Political Economy, vol. 109, no. 2, pp. 287-327, 2001.

[9] H. Clive, Private Participation in Infrastructure in Developing Countries, World Bank Working Paper, 2003.

[10] Barnes D. F., Transformative Power: Meeting the Challenge of Rural Electrification, Washington DC, USA, 2005, https://www .esmap.org/sites/esmap.org/files/KES02_TransformativePowerMeetingtheChallengeofRuralElectrification.pdf.

[11] R. Aldover, "Framework for Rural Energy Service Provision and Creating an Enabling Environment," in Seminar on Policy Options for the Expansion of Community-Driven Service Provision, UNESCAP, Beijing, China, March 2007.

[12] J. Maroušek, S. Hašková, R. Zeman, J. Váchal, and R. Vaníčková, "Assessing the implications of EU subsidy policy on renewable energy in Czech Republic," Clean Technologies and Environmental Policy, vol. 17, no. 2, pp. 549-554, 2015.

[13] S.-Y. Phang, "Urban rail transit PPPs: Survey and risk assessment of recent strategies," Transport Policy, vol. 14, no. 3, pp. 214-231, 2007. 
[14] A. M. Pagano, "Public-Private Partnerships (PPP) in Transportation: An Analysis of Alternatives," Journal of The Transportion Research Forum, vol. 49, no. 2, pp. 77-89, 2010, http:// citeseerx.ist.psu.edu/viewdoc/download?doi=10.1.1.451.2552\& amp;rep=rep1\&amp;type=pdf\#page $=79$.

[15] X. Meng, "Guarantees for contractor's performance and owner's payment in China," Journal of Construction Engineering and Management, vol. 128, no. 3, pp. 232-237, 2002.

[16] L. Myers and F. Najafi, "Performance bond benefit-cost analysis," Transportation Research Record, no. 2228, pp. 3-10, 2011.

[17] L. Shi, M. Onishi, and K. Kobayashi, "Payoff Externality and Performance-Based Contracts For Transport Infrastructure," International Journal of Transportation, vol. 3, no. 1, pp. 37-54, 2015.

[18] J. Song, D. Song, X. Zhang, and Y. Sun, "Risk identification for PPP waste-to-energy incineration projects in China," Energy Policy, vol. 61, pp. 953-962, 2013.

[19] A. Mahalingam, "PPP experiences in indian cities: Barriers, enablers, and the way forward," Journal of Construction Engineering and Management, vol. 136, no. 4, pp. 419-429, 2010.

[20] F.-M. Liou, C.-P. Huang, and B. Chen, "Modeling government subsidies and project risk for financially non-viable buildoperate-transfer (bot) projects," EMJ - Engineering Management Journal, vol. 24, no. 1, pp. 58-64, 2012.

[21] Y. Zhao and G. Ou, "Study on incentive subsidy mechanism of urban rail-transit," Journal of Beijing Jiaotong University (Social Sciences Edition), vol. 7, no. 2, pp. 10-16797, 2008.

[22] T. Couture and Y. Gagnon, "An analysis of feed-in tariff remuneration models: Implications for renewable energy investment," Energy Policy, vol. 38, no. 2, pp. 955-965, 2010.

[23] X. L. Wu, J. Zhou, Y. Peng, and Q. Duan, “Government's Compensation Mechanism for PPP Project Based on Game between Public and Private Sector," Chinese Journal of Management Science, pp. 198-204, 2013.

[24] M. Onishi, L. Shi, and K. Kobayashi, "The Impacts of Deposit and Subsidy Policy for Infrastructure PFI projects," Journal of Construction Management, vol. 12, pp. 149-158, 2005.

[25] J. E. Stiglitz, "Differential taxation, public goods, and economic efficiency," Review of Economic Studies, vol. 38, no. 2, pp. 151-174, 1971.

[26] A. B. Atkinson and N. H. Stern, "Pigou, taxation and public goods," Review of Economic Studies, vol. 41, no. 1, pp. 119-128, 1974.

[27] B. Fortin and G. Lacroix, "Labour supply, tax evasion and the marginal cost of public funds an empirical investigation," Journal of Public Economics, vol. 55, no. 3, pp. 407-431, 1994.

[28] H. J. Kleven and C. T. Kreiner, "The marginal cost of public funds: Hours of work versus labor force participation," Journal of Public Economics, vol. 90, no. 10-11, pp. 1955-1973, 2006. 


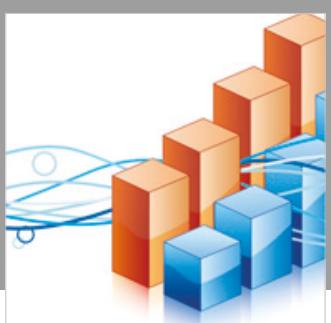

Advances in

Operations Research

\section{-n-m}
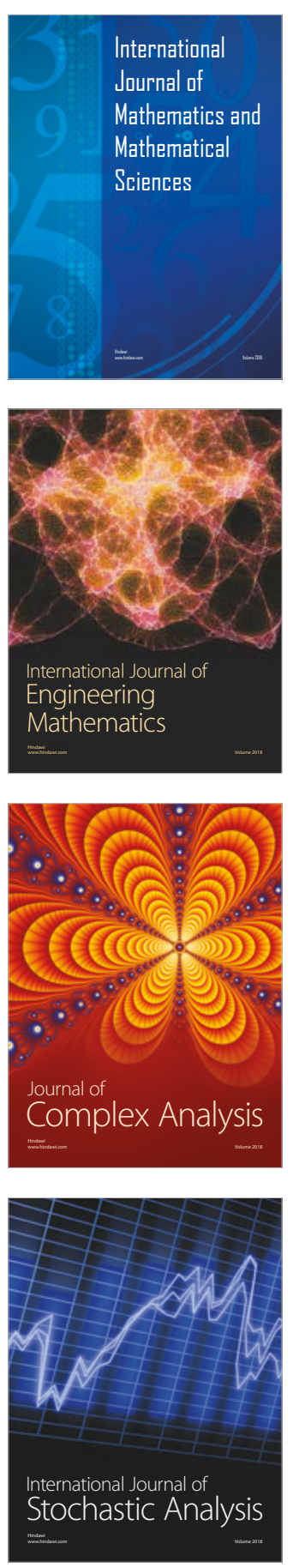
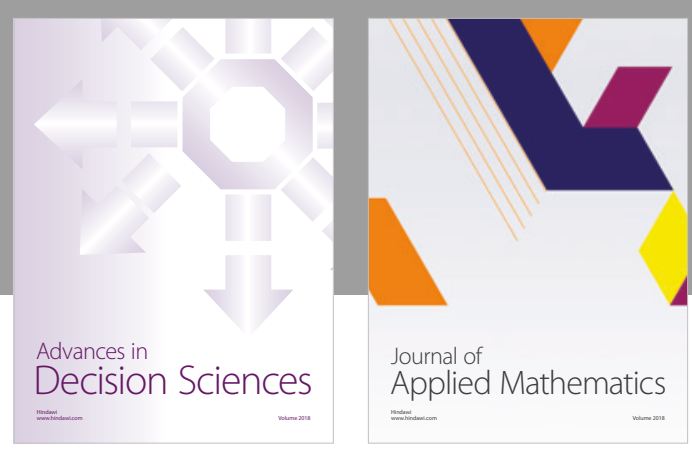

Journal of

Applied Mathematics
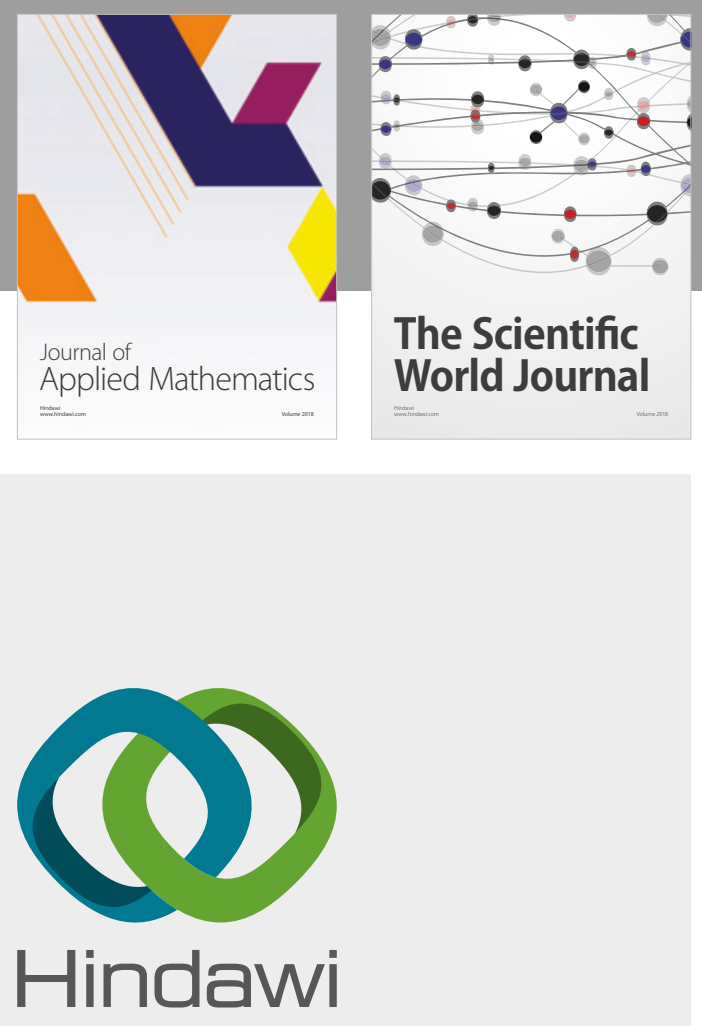

Submit your manuscripts at

www.hindawi.com

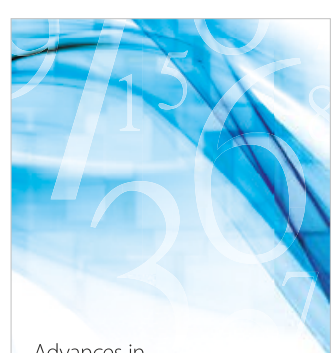

Advances in
Numerical Analysis
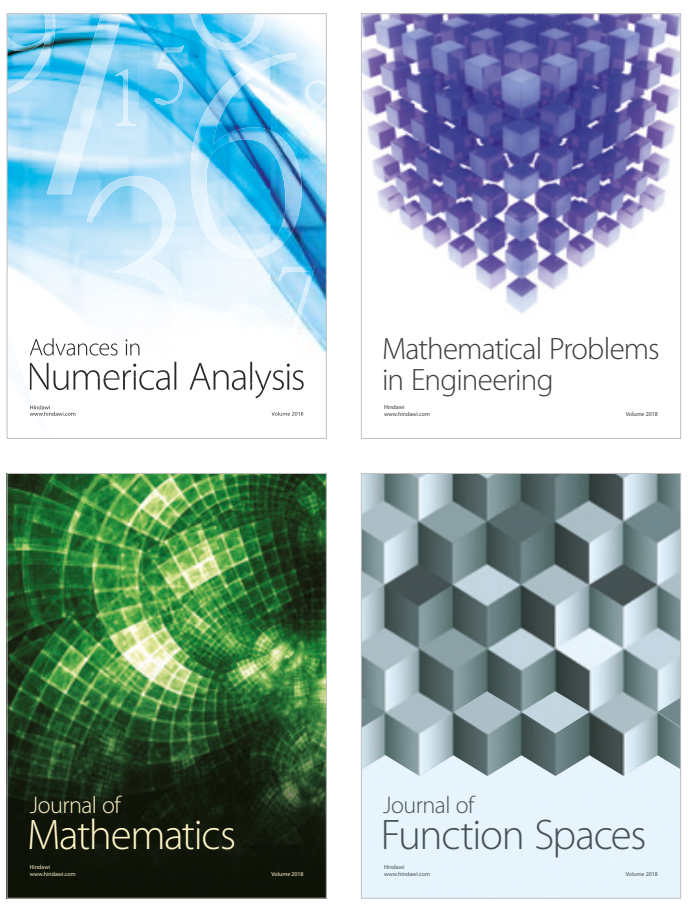

Mathematical Problems in Engineering

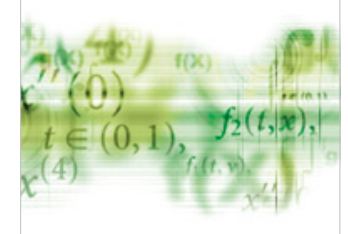

International Journal of

Differential Equations

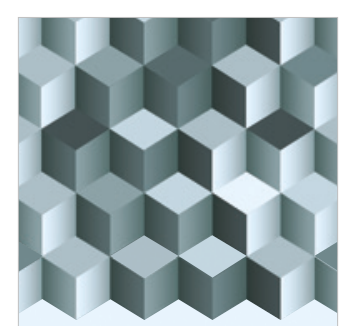

Journal of

Function Spaces

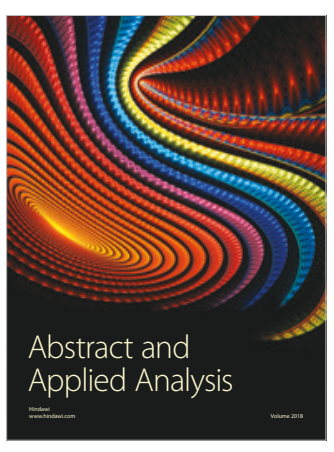

The Scientific

World Journal

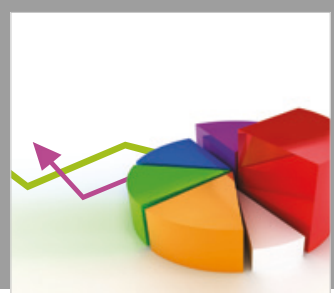

Journal of

Probability and Statistics
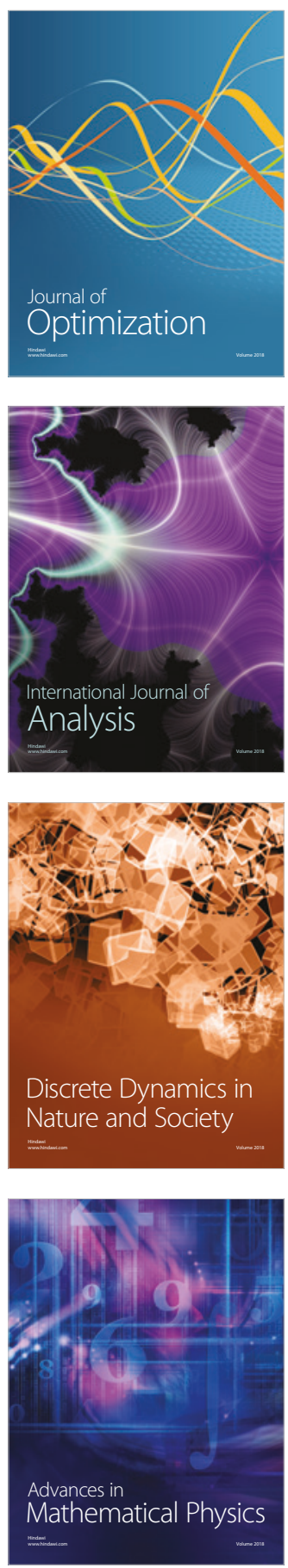